\title{
EGFR T790M: revealing the secrets of a gatekeeper
}

This article was published in the following Dove Press journal:

Lung Cancer:Targets and Therapy

9 October 2017

Number of times this article has been viewed

\section{Brian Ko \\ Daniel Paucar \\ Balazs Halmos}

Department of Oncology, Montefiore Medical Center, Albert Einstein College of Medicine, New York, NY, USA
Correspondence: Balazs Halmos Department of Oncology, Montefiore Medical Center, Albert Einstein College of Medicine, 1695 Eastchester Road, Bronx, New York, NY 1046I, USA $\mathrm{Tel}+\mathrm{I} 7184058404$

Fax +I 7I84058433

Email bahalmos@montefiore.org

\begin{abstract}
Non-small-cell lung cancers that harbor activating mutations in the EGFR gene represent an important molecularly defined subset of lung cancer. Despite dramatic initial responses with first- and second-generation EGFR-directed tyrosine-kinase inhibitors (TKIs) against these cancers, the development of a dominant and frequent resistance mechanism through a threoninemethionine amino acid substitution at position 790 (T790M) of EGFR has limited the long-term efficacy of these targeted therapies. This "gatekeeper" EGFR T790M alteration remains the only validated and relevant second-site resistance mutation for $E G F R$, allowing for focused research to understand and overcome EGFR T790M-mediated resistance. The current review focuses on EGFR T790M by discussing mechanisms of resistance mediated by EGFR T790M, reviewing development of novel third-generation EGFR TKIs targeting EGFR T790M, and highlighting current research on overcoming resistance to third-generation EGFR T790M TKIs.
\end{abstract}

Keywords: lung cancer, epidermal growth factor receptor, T790M, targeted therapy, resistance

\section{Introduction}

Numerous demonstrations of clinical efficacy with targeted therapies in a diverse range of cancer types have cemented molecularly targeted therapies as a major pillar in the treatment of many advanced solid-tumor and hematologic malignancies. For advanced non-small-cell lung cancers (NSCLCs) with certain activating mutations in the EGFR gene, first- and second-generation EGFR-directed tyrosine-kinase inhibitors (TKIs), including gefitinib, erlotinib, and afatinib ${ }^{1,2}$ have supplanted platinumcontaining chemotherapy regimens as first-line therapy, marking a major paradigm shift in the treatment of NSCLC. Unfortunately, despite initial clinical and radiological responses, resistance to first- and second-generation EGFR TKIs invariably develops, with median progression-free survival of $9-16$ months $^{3-6}$ and approximately $60 \%$ of patients developing resistance mediated by drug-induced selection of tumor-cell clones harboring a threonine-methionine amino-acid substitution at position 790 (T790M) of $E G F R$, which is the putative gatekeeper residue. ${ }^{7}$

The current review focuses on EGFR T790M. We first outline the treatment of $E G F R$-mutant NSCLC with first- and second-generation EGFR TKIs and the discovery of EGFR T790M as a dominant resistance mechanism to first- and second-generation EGFR TKI treatment. We then discuss mechanisms of resistance mediated by EGFR T790M and the development of novel third-generation EGFR TKIs targeting EGFR T790M. Next, we introduce novel methods for detecting EGFR T790M, along with appropriate workflows for incorporating molecular testing into clinical management. 
Lastly, we briefly highlight current research on overcoming resistance to third-generation EGFR T790M TKIs.

\section{Treatment of EGFR-mutant NSCLC with first- and second-generation EGFR TKIs}

EGFR is a cell-surface receptor belonging to the ErbB family of receptor TKs that also includes ErbB2/Her2/Neu, ErbB3/ Her3, and ErbB4/Her4. The binding of cognate ligands, such as EGF and TGF $\alpha$, induces a conformational change in EGFR that facilitates receptor homo- or heterodimer formation, in which the C-terminal lobe of one kinase domain of the asymmetric dimer complex plays a role analogous to that of cyclin in activated cyclin-dependent kinase complexes. ${ }^{8,9}$ Subsequently, activated EGFR can phosphorylate a range of substrates that results in the activation of multiple important downstream-signaling pathways within the cell, including the RAS-RAF-MEK-ERK pathway and the PI3K-AKTmTOR pathway, promoting cell proliferation and cell survival, respectively. With certain activating EGFR mutations, EGFR TK activity is permanently switched on, even in the absence of cognate ligands, through an intrinsic tendency to form asymmetric dimers, in which the C-terminal lobe of one kinase domain associates with the N-terminal lobe of a neighboring kinase domain, inducing an active conformation by orientating the regulatory C-helix to its inward position ${ }^{10}$ and resulting in inappropriate constitutive activation of oncogenic downstream-signaling pathways.

Tumor-associated EGFR mutations are present in approximately $10 \%-20 \%$ of NSCLC patients, ${ }^{1,2}$ with higher incidence in younger females, nonsmokers, and adenocarcinoma histology, occurring as frequently as $30 \%-50 \%$ in neversmokers with lung adenocarcinoma. ${ }^{11}$ These mutations most commonly occur within EGFR exons 18-21, which encode a critical portion of the EGFR-kinase domain, and usually do not occur concurrently with other NSCLC oncogenic mutations, such as $K R A S$ mutations and $A L K$-gene rearrangements. Approximately $90 \%$ of these mutations are EGFR exon 19 deletions or exon $21 \mathrm{~L} 858 \mathrm{R}$ point mutations, ${ }^{12}$ which increase the kinase activity of EGFR, leading to hyperactivation of downstream prosurvival signaling pathways, such as PI3K-AKT-mTOR and RAS-RAF-MEK-ERK, ${ }^{13}$ as well as induction of cyclin D1 expression. ${ }^{14}$ Through negativefeedback regulation, dual-specificity phosphatases, such as DUSP4 and DUSP6, can dampen excessive MAP-kinase signal transduction, while PHLDA1/2 can mitigate AKT activation. ${ }^{15-17}$ In addition, upregulation of the BH3-only polypeptide BIM correlates with gefitinib-induced apoptosis in gefitinib-sensitive $E G F R$-mutant lung cancer cells. ${ }^{18}$

Small-molecule adenosine triphosphate (ATP)-mimetic first-generation EGFR TKIs, such as gefitinib and erlotinib, inhibit EGFR TK activity by reversibly binding to the ATP-binding site of the receptor, while afatinib, a secondgeneration EGFR TKI, binds to the site irreversibly at aminoacid residue $\mathrm{C} 797$ at the cost of more severe epithelium-based toxicities (eg, rash, diarrhea) associated with increased binding to wild-type EGFR. In 2009, a pivotal Phase III study demonstrated superiority of gefitinib over carboplatinpaclitaxel as initial treatment for $E G F R$-mutated lung adenocarcinoma. The study was conducted among nonsmokers or former light smokers in East Asia with 12-month rates of progression-free survival of $24.9 \%$ with gefitinib and $6.7 \%$ with carboplatin-paclitaxel. In the subgroup of 261 patients with EGFR mutations, response rates were doubled and progression-free survival was significantly longer among those who received gefitinib than among those who received carboplatin-paclitaxel (HR for progression or death 0.48, 95\% CI 0.36-0.64; $P<0.001$ ), establishing frontline EGFR TKI therapy as the optimal choice for this group of patients and highlighting the critical need for molecular testing in patients with advanced NSCLC. ${ }^{3}$ Since then, these results have been replicated multiple times with gefitinib, erlotinib, and afatinib with the LUX-Lung $3^{19}$ and LUX-Lung $6^{20}$ studies, demonstrating improvements in overall survival in patients with $E G F R$ exon 19 deletion-positive tumors. Figure 1 summarizes the most clinically relevant $E G F R$ mutations and pictorially demonstrates the distinct molecular targets of various EGFR inhibitors.

\section{EGFR T790M as a resistance mechanism to first- and second- generation EGFRTKIs}

While first- and second-generation EGFR TKIs represent a prominent example of the clinical benefits targeted-therapy approaches can have on advanced oncogene-driven malignancies, the emergence of acquired resistance to these agents has prevented them from achieving long-term durable control of EGFR-mutant lung cancer. While approximately $60 \%-80 \%$ of patients with $E G F R$-mutant tumors initially respond to first- and second-generation EGFR TKIs with significant improvement in both objective response rates and progressionfree survival compared to upfront platinum-containing chemotherapy regimens, resistance invariably develops, with a median progression-free survival of 9-16 months..$^{3-6}$ 
A

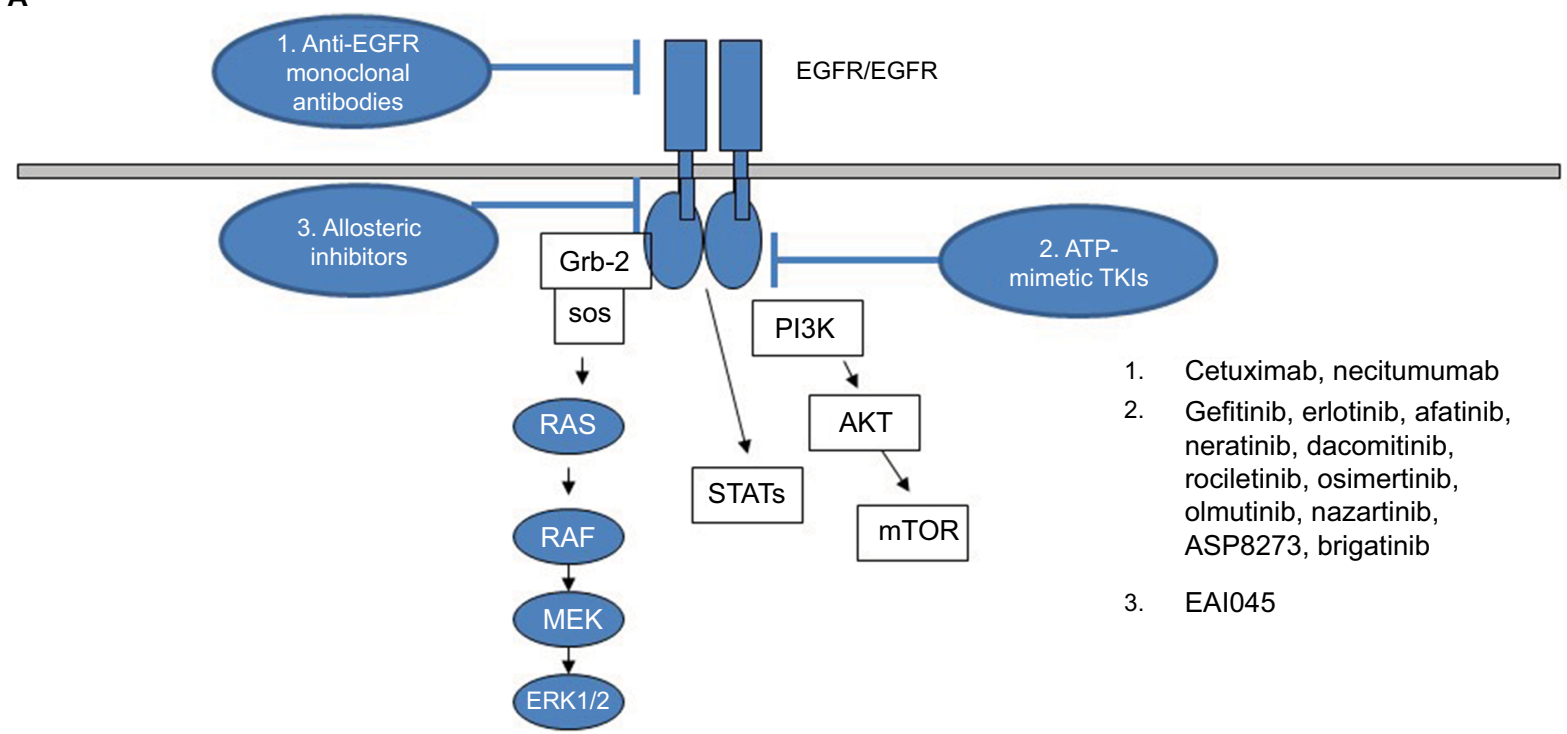

B

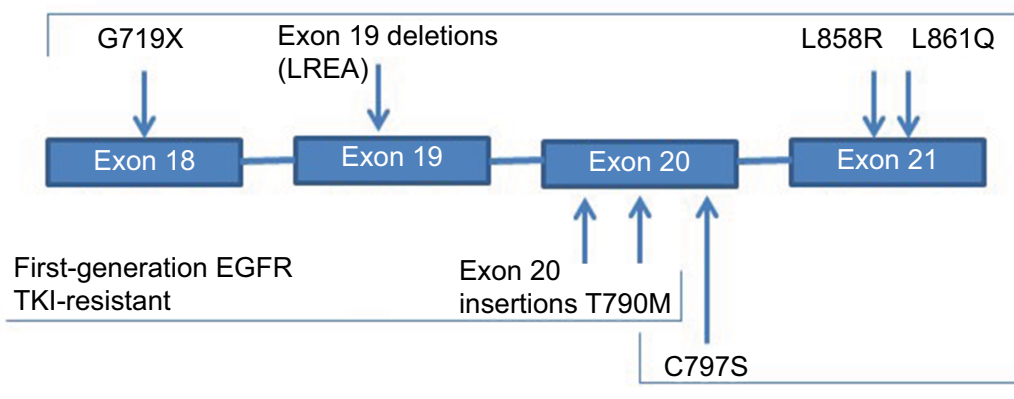

EGFR TKI-sensitive

Third-generation EGFR TKIresistant

Figure I Molecular targets of EGFR inhibitors (A); exon map of EGFR mutations (B). Abbreviation: TKI, tyrosine-kinase inhibitor.

First described in 2005, the most common mechanism of acquired resistance to first- and second-generation EGFR TKIs involves a threonine-methionine amino acid substitution at T790M of EGFR., ${ }^{7,21}$ Approximately $60 \%$ of patients treated with first- and second-generation EGFR TKIs harbor EGFR T790M mutations at the time of progression. ${ }^{22}$ In rare cases, $E G F R \mathrm{~T} 790 \mathrm{M}$ is reported as a germ-line alteration leading to a high lifetime risk of lung cancer, ${ }^{23}$ and recent research suggests that certain NSCLC tumors harbor genetically heterogeneous subclones with the EGFR T790M mutation at disease onset, instead of developing T790M de novo. Additionally, a subset of cells that are initially EGFR T790M-negative and survive EGFR TKI treatment can subsequently acquire $E G F R$ T790M for a fitness advantage, representing a population of drug-tolerant cells that can evolve further acquired resistance mechanisms in the context of drug-related selective pressure. ${ }^{24}$ Several studies suggest that EGFR T790M-positive lung cancers tend to have more indolent progression and better prognosis compared to EGFR T790M-negative lung cancers, ${ }^{25,26}$ as the development of EGFR T790M may require less complex genetic and molecular changes compared to other resistance mechanisms.

The biochemical mechanisms of EGFR T790Massociated resistance are likely multifactorial, including the popular "gatekeeper" hypothesis, which stipulates that there is steric clash between the larger methionine moiety (compared to threonine) on the gatekeeper side chain of EGFR T790M and the aniline moiety of first-generation EGFR TKIs. Other mechanisms include drastically increased ATPbinding affinity for $E G F R$ T790M, alterations in the catalytic domain, and changes in overall conformational dynamics. ${ }^{27} \mathrm{In}$ contrast to other targetable kinases, such as $\mathrm{ABL}$ in chronic myeloid leukemia and ALK in $A L K$ translocation-positive lung adenocarcinomas, in which a variety of second-site mutations can lead to resistance, ${ }^{28}$ EGFR T790M remains the only validated and relevant second-site resistance mutation for $E G F R$, as all other secondary mutations have been noted only in occasional case reports. This key dependence on T790M-mediated acquired resistance has allowed focused research into the development of T790M-targeting inhibitors. 


\section{Initial strategies to overcome EGFR T790M-mediated resistance}

Concurrent with the original discovery of EGFR T790M, it was noted that while T790M leads to very high-level resistance (1,000-fold) against reversible EGFR inhibitors, such as gefitinib and erlotinib, partial sensitivity was maintained with irreversible EGFR inhibitors, such as neratinib, dacomitinib, and afatinib. ${ }^{29,30}$ Studies with afatinib have focused on patients with clinically defined acquired resistance to first-generation EGFR TKIs. In the pivotal LUX-Lung 1 study, a significant prolongation of progression-free survival was noted compared to placebo, along with a $7 \%$ response rate; however, this did not translate into improved overall survival. ${ }^{6}$ Similarly, other second-generation EGFR TKIs did not reach critical milestones in development for this space. ${ }^{31}$ The reason for the poor efficacy of afatinib and similar drugs in this setting is more related to excessive potency against wild-type EGFR leading to substantial epithelium-based toxicities, rather than lack of efficacy against the mutant form. Principally, the therapeutic window in this setting is not sufficiently wide for significant clinical impact.

Based on transgenic mouse studies with preclinical models of EGFR T790M-mutated lung adenocarcinomas, ${ }^{32}$ the combination of afatinib and cetuximab was developed to provide needed synergy for enhanced clinical benefit. While studies of this combination demonstrated a significant improvement in response rates to more than $30 \%$ without significant differences between cases with or without documented EGFR T790M, ${ }^{33}$ the excessive toxicity of the combination has limited overall enthusiasm for further development.

\section{Targeting EGFR T790M with third- generation EGFR TKIs}

Recognizing the limitations of second-generation EGFR TKIs, third-generation EGFR TKIs were developed specifically to target $E G F R$ T790M and spare wild-type EGFR, thereby achieving much broader therapeutic windows compared to second-generation agents. Two compounds osimertinib (AZD9291) and rociletinib (CO-1686) - were the first to be introduced to the clinic. ${ }^{34,35}$ Both are irreversible covalent inhibitors of EGFR via binding to C797, allowing them to achieve sustained and complete EGFR inhibition, even in the presence of high intracellular concentrations of ATP, unlike gefitinib and erlotinib. Both osimertinib and rociletinib bind more avidly to EGFR T790M mutants than wild-type EGFR, mitigating some of the off-target effects associated with afatinib. ${ }^{27}$ Table 1 summarizes the relative differences in activity of multiple EGFR-directed therapies against various $E G F R$ mutations.

Osimertinib (AZD9291) is a monoanilinopyrimidine compound that has little activity against wild-type EGFR, but irreversibly and very potently inhibits $E G F R$ T790M and other common mutated forms of $E G F R$. It covalently binds cysteine 797 of $E G F R$, and has activity against some other kinases that harbor a cysteine residue in their analogous kinase domain, such as ErbB2, ErbB4, and BLK (formerly called BTK). Two circulating active metabolites, a desmethylindole analogue, AZ5104, and an $\mathrm{N}$-demethylated analogue, AZ7550, have been observed in both preclinical and clinical settings, with significant dose-dependent tumor regression in NSCLC cell lines with activating mutations of $E G F R$ and in tumor xenograft models. ${ }^{27}$

Despite tremendous initial excitement, clinical development of rociletinib was abruptly halted, due to high numbers of serious adverse events, including hyperglycemia and QT prolongation in clinical trials, which have been attributed to cross-reactivity with IGF1R. ${ }^{36,37}$ Osimertinib has a more favorable side-effect profile without cross-reactivity with IGF1R. Initial studies of osimertinib in an extended Phase I study of 253 patients with EGFR-mutated lung adenocarcinoma and resistance to prior EGFR TKI therapy demonstrated good tolerance across dose-escalation cohorts $(20-240 \mathrm{mg}$ ) without identified dose-limiting toxicities. ${ }^{38}$ Five doseexpansion cohorts demonstrated an objective response rate

Table I Relative qualitative activity of EGFR-directed therapies

\begin{tabular}{lll}
\hline & Wild-type EGFR & $\begin{array}{l}\text { Activating EGFR } \\
\text { mutations* }\end{array}$ \\
\hline Ist generation EGFR TKIs (e.g., gefitinib, erlotinib) & + & +++ \\
2nd generation EGFR TKIs (e.g., afatinib, dacomitinib) & ++ & + \\
3rd generation EGFR TKIs (e.g., osimertinib) & - & ++ \\
Anti-EGFR antibodies (e.g., cetuximab) & + & ++ \\
\hline
\end{tabular}

Notes: *Includes EGFR exon 19 deletions and insertions, exon 21 L858R and L86IQ, and exon I8 G7I9X; **EGFR C797S can occur in either trans or cis with EGFR T790M EGFR.

Abbreviation: TKIs, tyrosine-kinase inhibitors. 
of $51 \%$, and in patients with documented EGFR T790M this was even higher, at $61 \%$, with progression-free survival of 9.6 months (compared to $21 \%$ response rate for $E G F R$ T790M-negative patients and progression-free survival of 2.8 months). Subsequently, based on similar activity in the AURA extension and AURA2 studies, ${ }^{39}$ osimertinib obtained an accelerated US Food and Drug Administration (FDA) indication for the treatment of metastatic EGFR T790M mutation-positive NSCLC in patients who have progressed on or after EGFR TKI therapy. ${ }^{40}$ In both single-arm studies, osimertinib was administered at $80 \mathrm{mg}$ orally once daily, and objective response rates of $57 \%$ and $61 \%$ were noted in the AURA extension study and AURA2, respectively. Most observed adverse events were mild, and included diarrhea, rash, dry skin, and nail toxicities. Pneumonitis remains a concern like other EGFR TKIs, affecting a small percentage of patients (3.3\% in these two studies). Osimertinib is now the mainstay of therapy for EGFR T790M mutation-positive NSCLC.

In 2016, the AURA3 Phase III trial demonstrated that in patients with EGFR T790M-positive advanced NSCLC who had disease progression after first-line EGFR TKI therapy, the median duration of progression-free survival was significantly longer with osimertinib than with platinum-containing chemotherapy (cisplatin or carboplatin) plus pemetrexed (10.1 months vs 4.4 months, HR $0.3,95 \%$ CI $0.23-0.41$; $P<0.001$ ), with significantly longer median duration of progression-free survival in the subset of patients with central nervous system metastases ( 8.5 months vs 4.2 months, HR $0.32,95 \%$ CI $0.21-0.49)$. The objective response rate was also significantly better with osimertinib $(71 \%, 95 \% \mathrm{CI}$ $65 \%-76 \%$ ) than with platinum-containing chemotherapy plus pemetrexed (31\%, 95\% CI 24\%-40\%) (OR 5.39, 95\% CI $3.47-8.48 ; P<0.001)$. In addition, the proportion of patients with adverse events of grade 3 or higher was lower with osimertinib (23\%) than with platinum-containing chemotherapy plus pemetrexed (47\%). ${ }^{41}$ These outstanding results led to full FDA approval of osimertinib in 2017.

Many ongoing studies are exploring combinations of osimertinib with other agents that have established synergy in the management of advanced NSCLC, including bevacizumab, ramucirumab, and necitumumab, as well as combinations with other agents affecting pathways of resistance, such as MET inhibition and immune-checkpoint inhibition. While the relatively atoxic nature of osimertinib makes it an ideal partner for drug combinations, combination studies of osimertinib and durvalumab have demonstrated an unexpectedly high rate of interstitial lung disease. ${ }^{42} \mathrm{~A}$ range of clinical studies featuring osimertinib in combination with other agents are highlighted in Table 2.

\section{Other third-generation EGFR inhibitors in development}

Olmutinib (HM61713) is an irreversible EGFR TKI that (like osimertinib) binds $E G F R$ C797 and has preferential activity against all mutant forms of $E G F R$, including $E G F R$ T790M. In a Phase I/II study, $800 \mathrm{mg} /$ day was defined to be the recommended dose for further studies; at this dose level, olmutinib appears generally well tolerated, with rare cases of interstitial lung disease, but no documented cases of hyperglycemia. ${ }^{43} \mathrm{~A}$ total of 76 EGFR T790M-positive patients received therapy at the $800 \mathrm{mg} /$ day dose level, with an objective response rate of $54 \%$. Central nervous system activity was also noted, and based on these promising results, olmutinib gained approval

Table 2 Sampling of clinical studies targeting EGFR-mutated lung cancer

\begin{tabular}{|c|c|c|c|}
\hline Agent & Study & ClinicalTrials.gov & Key criteria \\
\hline $\begin{array}{l}\text { Osimertinib + } \\
\text { bevacizumab }\end{array}$ & $\begin{array}{l}\text { Osimertinib and bevacizumab as } \\
\text { treatment for EGFR-mutant lung } \\
\text { cancers }\end{array}$ & NCT02803203 & $\begin{array}{l}\text { - Advanced biopsy-proven metastatic NSCLC } \\
\text { - Somatic activating mutation in EGFR } \\
\text { - No prior treatment with an EGFR TKI or VEGF inhibitor }\end{array}$ \\
\hline $\begin{array}{l}\text { Osimertinib + } \\
\text { dasatinib }\end{array}$ & $\begin{array}{l}\text { Dasatinib and osimertinib } \\
\text { (AZD929I) in advanced NSCLC } \\
\text { with EGFR mutations }\end{array}$ & NCT02954523 & $\begin{array}{l}\text { - Confirmed advanced NSCLC } \\
\text { - Patients must have adequate archival material or fresh tissue to } \\
\text { determine EGFR-mutation status and Criptol expression } \\
\text { - Presence of sensitizing EGFR mutations (deletion in exon 19, } \\
\text { L858R in exon 2I, G7I9X, and L86IQ); patients with the } \\
\text { T790M mutation also eligible } \\
\text { - No prior treatment with an EGFR TKI for advanced NSCLC }\end{array}$ \\
\hline Osimertinib & $\begin{array}{l}\text { Neoadjuvant trial with AZD929I } \\
\text { in EGFR mutation-positive stage } \\
\text { IIIA/B NSCLC }\end{array}$ & NCT02824952 & $\begin{array}{l}\text { - Treatment-naive stage IIIA/B NSCLC with an activating } \\
\text { sensitizing EGFR T790M mutation (uncommon sensitizing EGFR } \\
\text { mutations allowed) } \\
\text { - Patients amenable to curative chemoradiotherapy }\end{array}$ \\
\hline
\end{tabular}


Table 2 (Continued)

\begin{tabular}{|c|c|c|c|}
\hline Agent & Study & ClinicalTrials.gov & Key criteria \\
\hline $\begin{array}{l}\text { Osimertinib + } \\
\text { INCB039I I0 }\end{array}$ & $\begin{array}{l}\text { Open-label Phase I/II study of } \\
\text { INCB039II0 in combination } \\
\text { with osimertinib in subjects with } \\
\text { NSCLC }\end{array}$ & NCT029I7993 & $\begin{array}{l}\text { - Confirmed unresectable locally advanced (stage IIIB) or } \\
\text { metastatic (stage IV) NSCLC } \\
\text { - Documented evidence of somatic activating mutation in EGFR } \\
\text { (eg, G7I9X, exon I9 deletion, L858R, L86IQ) in a tumor-tissue } \\
\text { sample or ctDNA } \\
\text { - Phase I: subjects must have previously received and progressed } \\
\text { on or after treatment with an EGFR TKI; additional lines of } \\
\text { systemic therapy, including investigational agents, for locally } \\
\text { advanced or metastatic NSCLC allowed } \\
\text { - Phase II: subjects must not have received more than one prior } \\
\text { line of therapy for locally advanced or metastatic NSCLC; first- } \\
\text { line treatment must include an EGFR TKI } \\
\text { - Evidence of T790M mutation in tumor tissue or plasma } \\
\text { obtained after disease progression during or after treatment } \\
\text { with an EGFR TKI }\end{array}$ \\
\hline $\begin{array}{l}\text { Osimertinib + } \\
\text { necitumumab or } \\
\text { ramucirumab }\end{array}$ & $\begin{array}{l}\text { Study of ramucirumab } \\
\text { (LY3009806) or necitumumab } \\
\text { (LY30122II) plus osimertinib in } \\
\text { participants with lung cancer }\end{array}$ & NCT02789345 & $\begin{array}{l}\text { - Diagnosis of NSCLC, with at least one measurable lesion by } \\
\text { RECIST I.I } \\
\text { - T790M-positive status after disease progression on EGFR TKI } \\
\text { treatment }\end{array}$ \\
\hline $\begin{array}{l}\text { Osimertinib + } \\
\text { navitoclax }\end{array}$ & $\begin{array}{l}\text { Osimertinib and navitoclax in } \\
\text { treating patients with EGFR- } \\
\text { positive previously treated } \\
\text { advanced or metastatic NSCLC }\end{array}$ & NCT02520778 & $\begin{array}{l}\text { - Nonsquamous NSCLC, with incurable advanced or metastatic } \\
\text { disease } \\
\text { - Positive for an EGFR-activating mutation (L858R, exon } 19 \\
\text { deletion, G7I9X, L86IQ) } \\
\text { - Progression after prior treatment with an EGFR TKI; in addition } \\
\text { to this one prior line of therapy, prior treatment with a third- } \\
\text { generation EGFR TKI allowed for dose-escalation phase, but } \\
\text { not permitted for expansion cohort }\end{array}$ \\
\hline Osimertinib & $\begin{array}{l}\text { AZD929I versus placebo in } \\
\text { patients with stage IB-IIIA } \\
\text { NSCLC, following complete } \\
\text { tumor resection with or } \\
\text { without adjuvant chemotherapy } \\
\text { (ADAURA) }\end{array}$ & NCT025III06 & $\begin{array}{l}\text { - Confirmed nonsquamous NSCLC. } \\
\text { - Patients must be classified postoperatively as stage IB, II, or IIIA } \\
\text { on the basis of pathologic criteria } \\
\text { - Confirmation that tumor harbors one of the two common } \\
\text { EGFR mutations (exon } 19 \text { deletion, L858R), either alone or in } \\
\text { combination with other EGFR mutations, including T790M }\end{array}$ \\
\hline $\begin{array}{l}\text { Osimertinib + } \\
\text { necitumumab }\end{array}$ & $\begin{array}{l}\text { EGFR inhibitor AZD929I and } \\
\text { necitumumab in treating patients } \\
\text { with EGFR-positive stage IV or } \\
\text { recurrent NSCLC who have } \\
\text { progressed on a previous EGFR } \\
\text { TKI }\end{array}$ & NCT02496663 & $\begin{array}{l}\text { - Patients with stage IV or recurrent/metastatic histologically } \\
\text { confirmed NSCLC } \\
\text { - At least one of the following EGFR-activating mutations: exon } \\
2 \text { I L858R, exon } 19 \text { deletion, exon I8 G7I9X, exon 2I L86IQ } \\
\text { - Progressive disease on at least one prior EGFR TKI } \\
\text { - Patients with treated brain metastases may be eligible }\end{array}$ \\
\hline $\begin{array}{l}\text { Osimertinib + } \\
\text { INKI } 28\end{array}$ & $\begin{array}{l}\text { TORCI/2 inhibitor INKI } 28 \text { and } \\
\text { EGFR inhibitor AZD929I in } \\
\text { treating patients with advanced } \\
\text { EGFR mutation-positive NSCLC } \\
\text { after progression on a previous } \\
\text { EGFR TKI }\end{array}$ & NCT02503722 & $\begin{array}{l}\text { - Confirmed diagnosis of advanced or metastatic nonsquamous } \\
\text { EGFR mutation (L858R, G7I9X, exon I9 deletion, L86IQ)- } \\
\text { positive NSCLC } \\
\text { - Patients with treated brain metastases may be eligible } \\
\text { - Dose-escalation phase: } \\
\text { - progressive disease on at least one prior EGFR TKI } \\
\text { administered for advanced/metastatic disease } \\
\text { - patients may have had more than one prior EGFR TKI therapy } \\
\text { and previous third-generation EGFR-TKIs permissible } \\
\text { - Dose-expansion phase: } \\
\text { - progressive disease on one prior EGFR TKI (erlotinib or } \\
\text { gefitinib or afatinib) } \\
\text { - prior therapy with third-generation TKI, including CO-I686; } \\
\text { AZD929I not permissible }\end{array}$ \\
\hline
\end{tabular}


Table 2 (Continued)

\begin{tabular}{|c|c|c|c|}
\hline Agent & Study & ClinicalTrials.gov & Key criteria \\
\hline $\begin{array}{l}\text { Osimertinib + } \\
\text { MEDI4736 }\end{array}$ & $\begin{array}{l}\text { Study of AZD929I plus } \\
\text { MEDI4736 versus AZD929I } \\
\text { monotherapy in NSCLC after } \\
\text { previous EGFR TKI therapy in } \\
\text { T790M mutation-positive tumors } \\
\text { (CAURAL) }\end{array}$ & NCT02454933 & $\begin{array}{l}\text { - Locally advanced/metastatic NSCLC, not amenable to curative } \\
\text { surgery or radiotherapy } \\
\text { - Confirmation that the tumor harbors an EGFR mutation known } \\
\text { to be associated with EGFR TKI sensitivity } \\
\text { - Progression while on a previous continuous treatment with } \\
\text { an EGFR TKI; additional other lines of therapy may have been } \\
\text { given } \\
\text { - Central lab confirmation of tumor T790M status from a biopsy } \\
\text { taken after disease progression on most recent treatment } \\
\text { regimen; only patients with } \mathrm{T790M}^{+} \text {to be included in the study }\end{array}$ \\
\hline $\begin{array}{l}\text { Osimertinib vs } \\
\text { gefitinib or erlotinib }\end{array}$ & $\begin{array}{l}\text { AZD929I versus gefitinib or } \\
\text { erlotinib in patients with locally } \\
\text { advanced or metastatic NSCLC } \\
\text { (FLAURA) }\end{array}$ & NCT02296I 25 & $\begin{array}{l}\text { - Pathologically confirmed adenocarcinoma of the lung } \\
\text { - Locally advanced or metastatic NSCLC, not amenable to } \\
\text { curative surgery or radiotherapy } \\
\text { - The tumor harbors one of the two common EGFR mutations } \\
\text { known to be associated with EGFR-TKI sensitivity (exon } 19 \\
\text { deletion, L858R) } \\
\text { - Patients must be treatment-naive for locally advanced or } \\
\text { metastatic NSCLC and eligible to receive first-line treatment } \\
\text { with gefitinib or erlotinib, as selected by the participating center }\end{array}$ \\
\hline EGF8I6 & $\begin{array}{l}\text { Phase I/II, multicenter, open- } \\
\text { label study of EGFR-mutant TKI } \\
\text { EGF8I6, administered orally in } \\
\text { adult patients with EGFR-mutant } \\
\text { solid malignancies }\end{array}$ & NCT02108964 & $\begin{array}{l}\text { - Histologically or cytologically confirmed locally advanced (stage } \\
\text { IIIB or metastatic stage IV) EGFR-mutant NSCLC } \\
\text { - Patients with controlled brain metastases may participate in the } \\
\text { trial }\end{array}$ \\
\hline $\begin{array}{l}\text { Nivolumab }+ \\
\text { EGF8I } 6 \text { or INC280 }\end{array}$ & $\begin{array}{l}\text { Study of efficacy and safety of } \\
\text { nivolumab in combination with } \\
\text { EGF8I } 6 \text { and of nivolumab in } \\
\text { combination with INC280 in } \\
\text { patients with previously treated } \\
\text { NSCLC (EGF8I6) }\end{array}$ & NCT02323I 26 & $\begin{array}{l}\text { - Patients with histologically documented locally advanced, } \\
\text { recurrent, and/or metastatic NSCLC } \\
\text { - Tumor tissue for determination and/or confirmation of genetic } \\
\text { prerequisites (ie, EGFR T790M positivity postprogression } \\
\text { on EGFR TKI for group I; cMet status for group 2) must be } \\
\text { provided for analysis } \\
\text { - Group I patients: } \\
\text { - patients with EGFR T790M NSCLC (adenocarcinoma) } \\
\text { - documented progression of disease according to RECIST I.I } \\
\text { following primary standard of care (eg, erlotinib, gefitinib) } \\
\text { - Group } 2 \text { patients: } \\
\text { - patients with EGFR wild-type NSCLC } \\
\text { focumented progression of disease according to RECIST I.I } \\
\text { following standard of care (eg, platinum doublet) }\end{array}$ \\
\hline EGF8I6 + INC280 & $\begin{array}{l}\text { Study of safety and efficacy of } \\
\text { EGF816 in combination with } \\
\text { INC280 in NSCLC patients with } \\
\text { EGFR mutation }\end{array}$ & NCT02335944 & $\begin{array}{l}\text { - Patients with histologically documented locally advanced or } \\
\text { recurrent (stage IIIB who are not eligible for combined modality } \\
\text { treatment) or metastatic (stage IV) NSCLC } \\
\text { - Patients must have locally documented EGFR L858R and/or } \\
\text { exon I9-deletion mutation, or a characterized de novo EGFR } \\
\text { T790M mutation (or other rare activating mutations that confer } \\
\text { sensitivity to first- and second-generation EGFR inhibitors (eg, } \\
\text { L86IQ, G7I9X, S768I) } \\
\text { - Phase II group I (EGFR-mutant, any T790M, any cMET, 2/4L } \\
\text { antineoplastic, EGFR TKI-resistant) only. } \\
\text { - Phase II Group } 2 \text { (EGFR-mutant, de novo T790M, any cMET, } \\
\text { I/3L antineoplastic, EGFR TKI-naive) only } \\
\text { - Phase II Group } 3 \text { (EGFR-mutant, T790M negative, any cMET, IL } \\
\text { antineoplastic) only }\end{array}$ \\
\hline
\end{tabular}


Table 2 (Continued)

\begin{tabular}{|c|c|c|c|}
\hline Agent & Study & ClinicalTrials.gov & Key criteria \\
\hline HM6I7I3 & $\begin{array}{l}\text { Phase II trial to evaluate the efficacy } \\
\text { and safety of HM6I7I3 as first-line } \\
\text { NSCLC anticancer therapy }\end{array}$ & NCT024448I9 & $\begin{array}{l}\text { - Cytologically or histologically confirmed advanced or metastatic } \\
\text { NSCLC not amenable to curative surgery (stage IIIB or IV) } \\
\text { - Documented EGFR mutations (excluding exon } 20 \text { insertion) }\end{array}$ \\
\hline HM6I7I3 & $\begin{array}{l}\text { Phase II trial of HM6I7I } 3 \text { for } \\
\text { treatment of } \geq \text { second-line } \\
\text { T790M mutation-positive } \\
\text { adenocarcinoma of the lung }\end{array}$ & NCT02485652 & $\begin{array}{l}\text { - Cytologically or histologically confirmed adenocarcinoma of } \\
\text { locally advanced or metastatic NSCLC not amenable to curative } \\
\text { surgery or radiotherapy } \\
\text { - Radiologically confirmed disease progression after at least one } \\
\text { line of treatment with an EGFR TKI } \\
\text { - At least one documented EGFR mutation known to be related } \\
\text { to susceptibility to EGFR TKIs (including G7I9X, exon } 19 \\
\text { deletion, L858R, and L86IQ) } \\
\text { Centrally confirmed T790M+ tumor status taken after } \\
\text { confirmation of disease progression on most recent anticancer- } \\
\text { treatment regimen }\end{array}$ \\
\hline ASP8273 & $\begin{array}{l}\text { Study of ASP8273 in EGFR } \\
\text { TKI-naive patients with NSCLC- } \\
\text { harboring EGFR mutations }\end{array}$ & NCT02500927 & $\begin{array}{l}\text { - Patients with histologically or cytologically confirmed diagnosis } \\
\text { of stage IIIB or IV NSCLC } \\
\text { - Patients confirmed to have exon I9 deletion, L858R, G7I9X, or } \\
\text { L86IQ mutation among the EGFR-activating mutations } \\
\text { - Patients who have not received previous treatment with } \\
\text { EGFR TKIs: erlotinib, gefitinib, afatinib, and EGFR TKIs under } \\
\text { clinical investigation (eg, neratinib, dacomitinib); EGFR TKIs } \\
\text { that can inhibit EGFR T790M mutation (eg, ASP8273, COI686, } \\
\text { AZD929I) also included } \\
\text { - Patients who have not received more than one regimen of } \\
\text { previous drug treatment }\end{array}$ \\
\hline $\begin{array}{l}\text { ASP } 8273 \text { vs } \\
\text { erlotinib or gefitinib }\end{array}$ & $\begin{array}{l}\text { Study of ASP8273 vs erlotinib or } \\
\text { gefitinib in first-line treatment of } \\
\text { patients with stage IIIB/IV NSCLC } \\
\text { tumors with EGFR-activating } \\
\text { mutations (SOLAR) }\end{array}$ & NCT0258826I & $\begin{array}{l}\text { - Subject has histologically confirmed locally advanced, metastatic } \\
\text { or unresectable stage IIIB/IV adenocarcinoma NSCLC (newly } \\
\text { diagnosed or recurrent); subjects with mixed histology eligible if } \\
\text { adenocarcinoma is the predominant histology } \\
\text { - Subject has an EGFR-activating mutation (exon I9 deletion or exon } \\
21 \text { L858R), with or without T790M mutation; subjects harboring } \\
\text { both exon } 19 \text { deletion and exon 2I L858R mutations not eligible }\end{array}$ \\
\hline PF-06747775 & $\begin{array}{l}\text { Study of patients with NSCLC } \\
\text { EGFR mutations (exon } 19 \text { deletion } \\
\text { or L858R } \pm \text { T790M) }\end{array}$ & NCT02349633 & $\begin{array}{l}\text { - Confirmed diagnosis of locally advanced or metastatic } \\
\text { EGFR-mutant (exon I9 deletion or L858R) NSCLC that has } \\
\text { progressed after at least one prior line of therapy } \\
\text { - Patients must have had disease progression on treatment with } \\
\text { an approved EGFR TKI } \\
\text { - Phase I: } \\
\text { - in dose-escalation and MTD-expansion portions, patients must } \\
\text { be T790M-positive or unknown status } \\
\text { - in PK sub-studies, patients with EGFR-mutant (exon } 19 \text { deletion } \\
\text { or L858R) NSCLC with any T790M status eligible to enroll } \\
\text { - Phase II: } \\
\text { - patients must have EGFR-mutant (exon } 19 \text { deletion and T790M } \\
\text { or L858R and T790M) NSCLC tumors }\end{array}$ \\
\hline ACOOIO & $\begin{array}{l}\text { Safety, tolerability, } \\
\text { pharmacokinetics, and antitumor } \\
\text { activity of ACOOIO in advanced } \\
\text { NSCLC }\end{array}$ & NCT02274337 & $\begin{array}{l}\text { - Confirmed metastatic or unresectable locally advanced } \\
\text { recurrent NSCLC } \\
\text { - Documented evidence of any activating EGFR mutation in tumor } \\
\text { tissue } \\
\text { - Have undergone or are able to undergo a biopsy of either primary } \\
\text { or metastatic tumor tissue within } 28 \text { days of avitinib dosing } \\
\text { - Disease progression under at least one treatment with current } \\
\text { marketed EGFR TKI therapy for at least } 30 \text { days (eg, erlotinib, } \\
\text { gefitinib, or afatinib) with intervening treatment after most } \\
\text { recent EGFR TKI therapy } \\
\text { - NSCLC patients with asymptomatic brain metastasis or drug- } \\
\text { controllable brain metastasis }\end{array}$ \\
\hline
\end{tabular}

Abbreviations: NSCLC, non-small-cell lung cancer; TKI, tyrosine-kinase inhibitor; RECIST, Response Evaluation Criteria In Solid Tumors. 
in South Korea in 2016. Current studies in the second-line (ELUXA 2) and frontline setting (ELUXA 1) are ongoing or recently completed. However, development of this drug in the US is currently on hold.

Nazartinib (EGF816) is another potent and selective $E G F R$-mutant inhibitor with irreversible binding to EGFR C797. ${ }^{44}$ Early-phase studies demonstrated promising activity, with an objective response rate of $46.9 \%$ and reported side effects of rash and diarrhea. Ongoing studies are exploring combination strategies with MET inhibitors and immunecheckpoint inhibitors.

ASP8273, which has mostly been developed in Asia, is another selective and potent third-generation EGFR inhibitor that has demonstrated good tolerance and excellent activity in early-phase studies, with an objective response rate of $64 \%$ in 70 EGFR T790M-positive patients treated at a dose of $300 \mathrm{mg} /$ day. Current development focuses on first-line indication, with an ongoing pivotal Phase III study (SOLAR) comparing ASP8273 to gefitinib/erlotinib in treatment-naive patients with EGFR-mutation positive NSCLC.

\section{Methods of detecting EGFR T790M}

Given the high objective response rates of EGFR T790M mutation-positive lung cancers to osimertinib, it is crucial to accurately identify tumors that harbor EGFR T790M. Until recently, the standard of care for detecting EGFR T790M at the time of disease progression on EGFR TKI therapy was via tissue biopsy followed by sequencing using a range of testing platforms with differing sensitivities for the detection of subclonal presence of mutations. However, invasive biopsies cannot be performed in all patients (eg, tumors in anatomic locations that are difficult to access, very small metastatic lesions), and are associated with significant risks, such as bleeding, lung injury, and pneumothoraces. They can also inadequately sample genomically heterogeneous tumors, and might not accurately reflect tumor heterogeneity within a single patient. In addition, a single-biopsy procedure may provide insufficient material for the required battery of genetic and immunochemistry assays. With increasing recognition that serial molecular assessments are necessary to tailor treatments appropriately for lung cancer throughout the disease course, ${ }^{22}$ serial invasive biopsies represent a significant practical barrier in clinical care.

To address this problem directly, clinical development of noninvasive methods to detect genomic aberrations accurately is active in a wide range of tumor types, including isolation of circulating tumor cells (CTCs) and both plasma-based and urine-based ctDNA assays. While all cells shed short (usually 150-170 base pairs in length) doublestranded DNA fragments called cfDNA into the systemic circulation, ${ }^{45,46}$ malignant cells from primary and metastatic tumors shed CTCs and ctDNA, providing potential sources of systemic tumor-derived genetic material that carries mutations representative of tumor biology. ${ }^{47}$ In fact, ctDNA may more accurately reflect tumor heterogeneity within a given patient, and multiple studies have demonstrated that increasing solid-tumor burden is associated with higher detected levels of cfDNA and ctDNA. While capturing an adequate numbers of CTCs from blood samples has been a difficult technical challenge, more sensitive microfluidic-based platforms ${ }^{48}$ have further opened the possibility of noninvasive blood-based testing in combination with modern genotyping assays. In patients with advanced NSCLC, ctDNA-detection rates ranging from $80 \%$ to over $95 \%$ have been reported using current detection assays. ${ }^{49,50}$ With rapid progress in ctDNAbased technologies, multiple plasma-based, urine-based, and cerebrospinal fluid-based testing platforms have entered the clinical arena over the last few years. There are many platforms available or in active development based on droplet digital polymerase chain reaction and massively parallel DNA sequencing, otherwise known as next-generation sequencing, including cancer personalized profiling by deep sequencing, which can simultaneously detect insertions, deletions, rearrangements, single-nucleotide variants, and somatic copynumber alterations to examine a diverse array of potential resistance mechanisms. ${ }^{51}$ Key registration research utilized the Cobas EGFR-mutation test, which uses tumor tissue or plasma to detect 42 mutations in exons $18-21$ of the EGFR gene, including T790M. ${ }^{52}$

In a prospective, multicenter exploratory analysis of 40 patients with EGFR-mutant tumors that had progressed on first- or second-generation EGFR TKIs, blood samples were drawn for CTC and ctDNA analyses at the same time as tumor biopsy to assess $E G F R$ T790M test characteristics and concordance among the three diagnostic modalities. Interestingly, no clear "gold standard" emerged, and mutation data among tissue-based and blood-based analyses provided nonoverlapping and complementary information, as the noninvasive blood-based analyses identified the $E G F R$ T790M mutation in 14 (35\%) of patients who had negative or indeterminate invasive tumor biopsies. ${ }^{53}$ Further validation studies are clearly warranted, but it appears that the concurrent use of noninvasive blood-based analyses may help provide a more complete assessment of the biology of a given patient's $E G F R$-mutant tumors. Indeed, FDA approval for the tissue and blood-based Cobas EGFR-mutation ctDNA 
assay has been secured in 2016, based on the aforementioned studies. Figure 2 provides a brief flowchart that demonstrates how ctDNA testing could be incorporated into the clinical management workflow for advanced NSCLC.

\section{Acquired resistance to EGFR T790M-targeting TKIs}

Unfortunately, novel acquired resistance mechanisms are emerging in specific response to EGFR T790M-directed therapy as well. For patients with EGFR T790M-positive lung cancer treated with osimertinib, progression-free survival usually ranges from 10 to 12 months. Tumor samples from patients treated with osimertinib and rociletinib during Phase I studies revealed several distinct acquired-resistance mechanisms, including the key EGFR C797S mutation, which drastically reduces the efficacy of all third-generation EGFR inhibitors. ${ }^{51,54}$ The detected frequency of C797S varied from study to study with different molecular monitoring methods, but it has been reported to be as high as $22 \%$. Intriguingly, the allelic context of the occurrence of C797S might have treatment implications. ${ }^{55}$ If EGFR C797S occurs in trans with EGFR T790M on a different allele, the cells might retain sensitivity to a combination of first- and third-generation EGFR inhibitors. If the mutations are on the same allele in cis, high-level resistance is expected against all currently used EGFR TKIs; recent data suggest that most EGFR C797S mutations are occurring in cis. While tissue-based $E G F R$ sequencing remains the standard, ctDNA approaches in this context are gaining clear importance. Since ctDNA exists typically as 150-170 base-pair fragments, the proximity of EGFR T790 and EGFR C797 allows these allelic relationships to be readily assessed. Interestingly, this EGFR C797S-resistance mutation is analogous to the recently described BTK-resistance mutation, C481S, which arises in the context of the BTK inhibitor ibrutinib in chronic lymphocytic leukemia. ${ }^{56}$

Besides EGFR C797S, multiple other resistance mechanisms to osimertinib therapy have been documented in case reports and case series, mirroring what has been reported with first-generation EGFR inhibitors. ${ }^{57}$ As anticipated, MET amplification, SC transformation, and downstream mutations in $B R A F$ and $P I 3 K$ have been noted. In addition to $\mathrm{C} 797 \mathrm{~S}$, other EGFR mutations such as L792F might represent alternative resistance mechanisms. ctDNA platforms greatly accelerate the discovery of these mechanisms, and need to be integrated into ongoing studies. ${ }^{58,59}$ In addition,

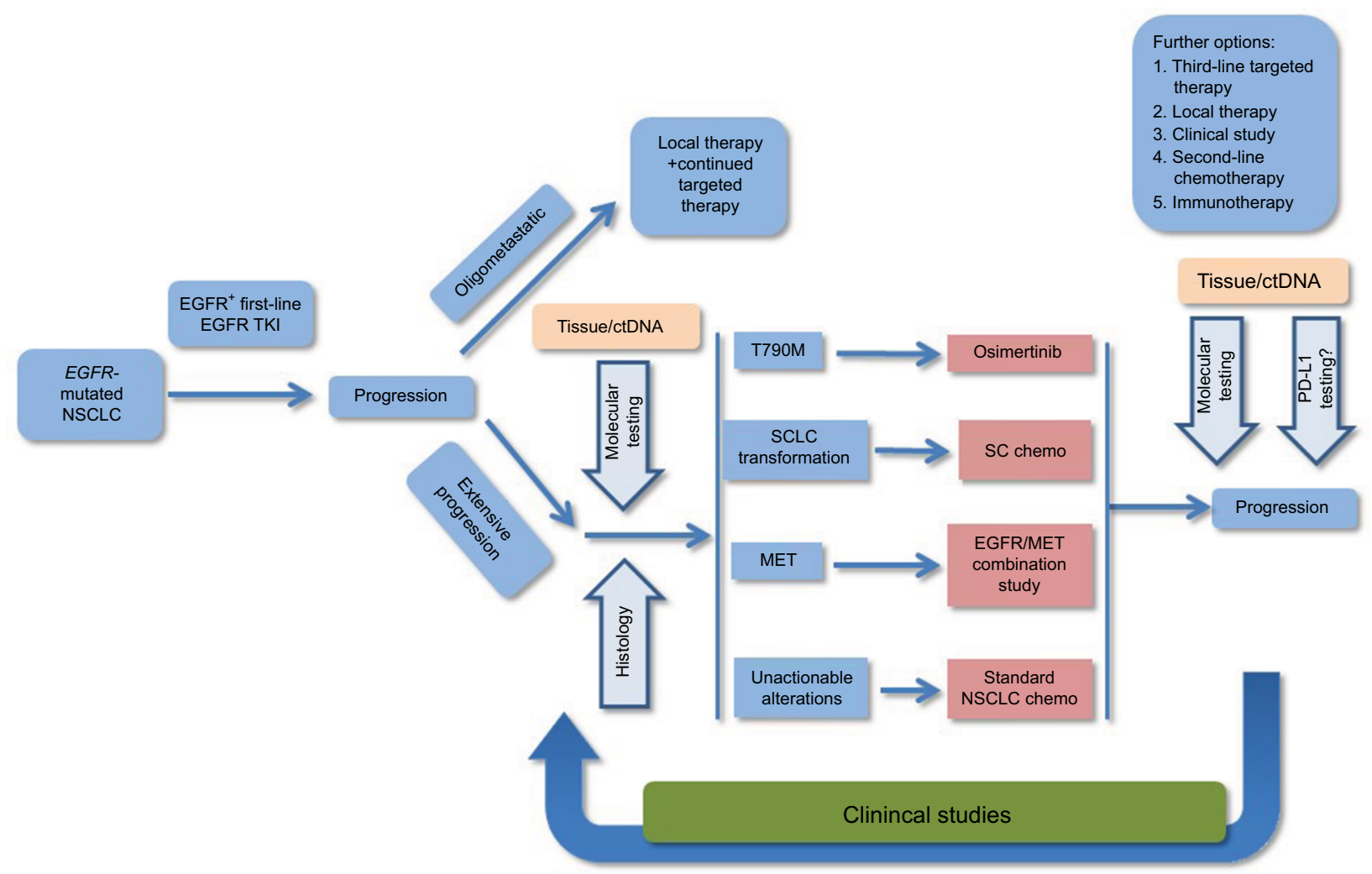

Figure 2 Flowchart for management of advanced NSCLC.

Abbreviations: NSCLC, non-small-cell lung cancer; SCLC, small cell lung cancer; SC, small cell; TKI, tyrosine-kinase inhibitor. 
an interesting and recurrent observation has been that upon the development of resistance to EGFR T790M-directed therapy, the original T790M-mutated clone often becomes undetectable, highlighting some potential for retreatment with earlier-generation drugs for certain patients.

\section{Overcoming resistance to EGFR T790M-targeting TKIs}

Since all currently FDA-approved EGFR TKIs target the ATP site of EGFR, a promising drug-discovery strategy involves the development of allosteric inhibitors that selectively target drug-resistant EGFR mutants while binding less avidly to wild-type EGFR. One such lead compound, EAI045, binds an allosteric site on the inactive conformation of EGFR and inhibits L858R/T790M-mutant EGFR with low-nanomolar potency (but not exon 19 deletion/T790M) ${ }^{60}$ However, as a single agent, EAI045 is ineffective in targeting EGFR asymmetric dimers and cannot block EGFR-driven cell proliferation. In combination with cetuximab, a recombinant human/ mouse chimeric monoclonal antibody, which binds EGFR and prevents EGFR dimerization by competitively inhibiting the binding of cognate ligands, EAI045 effectively blocks EGFR-driven cell proliferation in mouse models of lung cancer driven by both L858R/T790M EGFR and L858R/ T790M/C797S EGFR. Analogous to prior discussions with afatinib, resistant cells with T790M/C797S EGFR remain partially sensitive to cetuximab because of the disruption of EGFR dimerization. The combination of EAI045 and cetuximab demonstrated significant synergy in these elegant studies, and represents a possible approach to circumventing acquired resistance mediated by EGFR C797S.

Another promising approach utilizes the combination of the highly potent and selective $A L K / E G F R$ T790M inhibitor brigatinib, along with cetuximab. ${ }^{61}$ While brigatinib has demonstrated modest efficacy as a single agent in early studies focused on EGFR T790M-positive patients, in an in vitro drug-screening $\mathrm{Ba} / \mathrm{F} 3$ cell-line model it had the best efficacy among all screened compounds against triple-EGFR mutation-positive cells and structural prediction models suggest that this might be related to a better fit without steric crowding in the context of T790M and/ or C797S compared to other EGFR inhibitors. While the in vitro efficacy of brigatinib monotherapy might not be clinically meaningful, given high required concentrations, concurrent treatment with cetuximab led to substantial synergy, yielding a potentially meaningful $\mathrm{IC}_{50}$ in the hundred-nanomolar range.

\section{Conclusion}

Since the original discovery of the pivotal EGFR T790M mutation driving acquired resistance in most EGFR-mutated lung adenocarcinomas exposed to first- or second-generation EGFR TKI therapy, a tremendous amount has been learned about the mechanism and biology of resistance. Tissue- and ctDNA-based testing for EGFR T790M has now become the standard of care. The high frequency of this key gatekeeper mutation permitted successful development of effective drugs specifically targeting this molecular aberration, yielding highly potent and safe drugs, such as osimertinib, that are extending the benefits of EGFR-directed therapy. Osimertinib will likely move into earlier lines of therapy, and rational drug combinations are now being developed to overcome and prevent such molecularly driven resistance. Lastly, the paradigm shift defined by acquired resistance via $E G F R$ T790M has allowed rapid evolution of analogous knowledge for third-generation EGFR inhibitors. These lessons will continue to provide valuable insight into many other molecularly defined subsets of patients with a wide range of solid and hematological malignancies.

\section{Disclosure}

$\mathrm{BH}$ has received consulting fees from Foundation One, Genoptix, Boehringer-Ingelheim, Takeda, Novartis, AstraZeneca, Genentech, Pfizer, and Eli-Lilly, and research support from Merck, Bristol-Myers-Squibb, Pfizer, Mirati, Takeda, AstraZeneca, Boehringer-Ingelheim, Novartis, Eli-Lilly, and Genentech. The other authors report no conflicts of interest in this work.

\section{References}

1. Paez JG, Jänne PA, Lee JC, et al. EGFR mutations in lung cancer: correlation with clinical response to gefitinib therapy. Science. 2004;304(5676):1497-1500.

2. Lynch TJ, Bell DW, Sordella R, et al. Activating mutations in the epidermal growth factor receptor underlying responsiveness of non-small-cell lung cancer to gefitinib. $N$ Engl J Med. 2004;350(21):2129-2139.

3. Mok TS, Wu YL, Thongprasert S, et al. Gefitinib or carboplatin-paclitaxel in pulmonary adenocarcinoma. $N$ Engl J Med. 2009;361(10):947-957.

4. Maemondo M, Inoue A, Kobayashi K, et al. Gefitinib or chemotherapy for non-small-cell lung cancer with mutated EGFR. $N$ Engl J Med. 2010;362(25):2380-2388.

5. Rosell R, Carcereny E, Gervais R, et al. Erlotinib versus standard chemotherapy as first-line treatment for European patients with advanced EGFR mutation-positive non-small-cell lung cancer (EURTAC): a multicentre, open-label, randomised phase 3 trial. Lancet Oncol. 2012;13(3):239-246.

6. Miller VA, Hirsh V, Cadranel J, et al. Afatinib versus placebo for patients with advanced, metastatic non-small-cell lung cancer after failure of erlotinib, gefitinib, or both, and one or two lines of chemotherapy (LUXLung 1): a phase 2B/3 randomised trial. Lancet Oncol. 2012;13(5): 528-538. 
7. Kobayashi S, Boggon TJ, Dayaram T, et al. EGFR mutation and resistance of non-small-cell lung cancer to gefitinib. $N$ Engl $J$ Med. 2005;352(8):786-792.

8. Zhang X, Gureasko J, Shen K, Cole PA, Kuriyan J. An allosteric mechanism for activation of the kinase domain of epidermal growth factor receptor. Cell. 2006;125(6):1137-1149.

9. Kumar A, Petri ET, Halmos B, Boggon TJ. Structure and clinical relevance of the epidermal growth factor receptor in human cancer. J Clin Oncol. 2008;26(10):1742-1751.

10. Park JH, Liu Y, Lemmon MA, Radhakrishnan R. Erlotinib binds both inactive and active conformations of the EGFR tyrosine kinase domain. Biochem J. 2012;448(3):417-423.

11. D'Angelo SP, Pietanza MC, Johnson ML, et al. Incidence of EGFR exon 19 deletions and L858R in tumor specimens from men and cigarette smokers with lung adenocarcinomas. J Clin Oncol. 2011;29(15): 2066-2070.

12. Ladanyi M, Pao W. Lung adenocarcinoma: guiding EGFR-targeted therapy and beyond. Mod Pathol. 2008;21 Suppl 2:S16-S22.

13. Sordella R, Bell DW, Haber DA, Settleman J. Gefitinib-sensitizing EGFR mutations in lung cancer activate anti-apoptotic pathways. Science. 2004;305(5687):1163-1167.

14. Kobayashi S, Shimamura T, Monti S, et al. Transcriptional profiling identifies cyclin D1 as a critical downstream effector of mutant epidermal growth factor receptor signaling. Cancer Res. 2006;66(23):11389-11398.

15. Zhang Z, Kobayashi S, Borczuk AC, et al. Dual specificity phosphatase 6 (DUSP6) is an ETS-regulated negative feedback mediator of oncogenic ERK signaling in lung cancer cells. Carcinogenesis. 2010;31(4): $577-586$.

16. Chitale D, Gong Y, Taylor BS, et al. An integrated genomic analysis of lung cancer reveals loss of DUSP4 in EGFR-mutant tumors. Oncogene. 2009;28(31):2773-2783.

17. Li G, Wang X, Hibshoosh H, Jin C, Halmos B. Modulation of ErbB2 blockade in ErbB2-positive cancers: the role of ErbB2 mutations and PHLDA1. PLoS One. 2014;9(9):e106349.

18. Costa DB, Halmos B, Kumar A, et al. BIM mediates EGFR tyrosine kinase inhibitor-induced apoptosis in lung cancers with oncogenic EGFR mutations. PLoS Med. 2007;4(10):1669-1680.

19. Sequist LV, Yang JC, Yamamoto N, et al. Phase III study of afatinib or cisplatin plus pemetrexed in patients with metastatic lung adenocarcinoma with EGFR mutations. J Clin Oncol. 2013;31(27): 3327-3334.

20. Wu YL, Zhou C, Hu CP, et al. Afatinib versus cisplatin plus gemcitabine for first-line treatment of Asian patients with advanced non-small-cell lung cancer harbouring EGFR mutations (LUX-Lung 6): an open-label, randomised phase 3 trial. Lancet Oncol. 2014;15(2):213-222.

21. Pao W, Miller VA, Politi KA, et al. Acquired resistance of lung adenocarcinomas to gefitinib or erlotinib is associated with a second mutation in the EGFR kinase domain. PLoS Med. 2005;2(3):e73.

22. Sequist LV, Waltman BA, Dias-Santagata D, et al. Genotypic and histological evolution of lung cancers acquiring resistance to EGFR inhibitors. Sci Transl Med. 2011;3(75):75ra26.

23. Bell DW, Gore I, Okimoto RA, et al. Inherited susceptibility to lung cancer may be associated with the T790M drug resistance mutation in EGFR. Nat Genet. 2005;37(12):1315-1316.

24. Hata AN, Niederst MJ, Archibald HL, et al. Tumor cells can follow distinct evolutionary paths to become resistant to epidermal growth factor receptor inhibition. Nat Med. 2016;22(3):262-269.

25. Oxnard GR, Arcila ME, Sima CS, et al. Acquired resistance to EGFR tyrosine kinase inhibitors in EGFR-mutant lung cancer: distinct natural history of patients with tumors harboring the T790M mutation. Clin Cancer Res. 2011;17(6):1616-1622.

26. Hata A, Katakami N, Yoshioka H, et al. Rebiopsy of non-small cell lung cancer patients with acquired resistance to epidermal growth factor receptor-tyrosine kinase inhibitor: comparison between T790M mutation-positive and mutation-negative populations. Cancer. 2013;119(24):4325-4332.
27. Cheng H, Nair SK, Murray BW. Recent progress on third generation covalent EGFR inhibitors. Bioorg Med Chem Lett. 2016;26(8):1861-1868.

28. Gainor JF, Dardaei L, Yoda S, et al. Molecular mechanisms of resistance to first- and second-generation ALK inhibitors in ALK-rearranged lung cancer. Cancer Discov. 2016;6(10):1118-1133.

29. Kwak EL, Sordella R, Bell DW, et al. Irreversible inhibitors of the EGF receptor may circumvent acquired resistance to gefitinib. Proc Natl Acad Sci U S A. 2005;102(21):7665-7670.

30. Kobayashi S, Ji H, Yuza Y, et al. An alternative inhibitor overcomes resistance caused by a mutation of the epidermal growth factor receptor. Cancer Res. 2005;65(16):7096-7101.

31. Ou SH, Soo RA. Dacomitinib in lung cancer: a "lost generation" EGFR tyrosine-kinase inhibitor from a bygone era? Drug Des Devel Ther. 2015;9:5641-5653.

32. Regales L, Gong Y, Shen R, et al. Dual targeting of EGFR can overcome a major drug resistance mutation in mouse models of EGFR mutant lung cancer. J Clin Invest. 2009;119(10):3000-3010.

33. Janjigian YY, Smit EF, Groen HJ, et al. Dual inhibition of EGFR with afatinib and cetuximab in kinase inhibitor-resistant EGFR-mutant lung cancer with and without T790M mutations. Cancer Discov. 2014;4(9): 1036-1045.

34. Cross DA, Ashton SE, Ghiorghiu S, et al. AZD9291, an irreversible EGFR TKI, overcomes T790M-mediated resistance to EGFR inhibitors in lung cancer. Cancer Discov. 2014;4(9):1046-1061.

35. Walter AO, Sjin RT, Haringsma HJ, et al. Discovery of a mutant-selective covalent inhibitor of EGFR that overcomes T790M-mediated resistance in NSCLC. Cancer Discov. 2013;3(12):1404-15.

36. Sequist LV, Goldman JW, Wakelee HA, et al. Efficacy of rociletinib (CO-1686) in plasma-genotyped T790M-positive non-small cell lung cancer (NSCLC) patients (pts). J Clin Oncol. 2015;33 Suppl:8001.

37. Van Der Steen N, Caparello C, Rolfo C, Pauwels P, Peters GJ, Giovannetti E. New developments in the management of non-small-cell lung cancer, focus on rociletinib: what went wrong? Onco Targets Ther. 2016;9:6065-6074.

38. Jänne PA, Yang JC, Kim DW, et al. AZD9291 in EGFR inhibitor-resistant non-small-cell lung cancer. $N$ Engl J Med. 2015;372(18):1689-1699.

39. Goss G, Tsai CM, Shepherd FA, et al. Osimertinib for pretreated EGFR Thr790Met-positive advanced non-small-cell lung cancer (AURA2): a multicentre, open-label, single-arm, phase 2 study. Lancet Oncol. 2016;17(12):1643-1652.

40. Khozin S, Weinstock C, Blumenthal GM, et al. Osimertinib for the treatment of metastatic epidermal growth factor T970M positive nonsmall cell lung cancer. Clin Cancer Res. Epub 2016 Dec 6.

41. Mok TS, Wu YL, Ahn MJ, et al. Osimertinib or platinum-pemetrexed in EGFR T790M-positive lung cancer. N Engl J Med. 2017;376(7):629-640.

42. Ahn MJ, Sun JM, Lee SH, Ahn JS, Park K. EGFR TKI combination with immunotherapy in non-small cell lung cancer. Expert Opin Drug Saf. 2017;16(4):465-469.

43. Tan CS, Cho BC, Soo RA. Next-generation epidermal growth factor receptor tyrosine kinase inhibitors in epidermal growth factor receptormutant non-small cell lung cancer. Lung Cancer. 2016;93:59-68.

44. Jia Y, Juarez J, Li J, et al. EGF816 exerts anticancer effects in non-small cell lung cancer by irreversibly and selectively targeting primary and acquired activating mutations in the EGF receptor. Cancer Res. 2016;76(6):1591-1602.

45. Levy B, Hu ZI, Cordova KN, Close S, Lee K, Becker D. Clinical utility of liquid diagnostic platforms in non-small cell lung cancer. Oncologist. 2016;21(9):1121-1130.

46. Chandrananda D, Thorne NP, Bahlo M. High-resolution characterization of sequence signatures due to non-random cleavage of cell-free DNA. BMC Med Genomics. 2015;8:29.

47. Diaz LA Jr, Bardelli A. Liquid biopsies: genotyping circulating tumor DNA. J Clin Oncol. 2014;32(6):579-586.

48. Stott SL, Hsu CH, Tsukrov DI, et al. Isolation of circulating tumor cells using a microvortex-generating herringbone-chip. Proc Natl Acad Sci US A. 2010;107(43):18392-18397.

49. Newman AM, Bratman SV, To J, et al. An ultrasensitive method for quantitating circulating tumor DNA with broad patient coverage. Nat Med. 2014;20(5):548-554. 
50. Thompson JC, Yee SS, Troxel AB, et al. Detection of therapeutically targetable driver and resistance mutations in lung cancer patients by next-generation sequencing of cell-free circulating tumor DNA. Clin Cancer Res. 2016;22(23):5772-5782.

51. Chabon JJ, Simmons AD, Lovejoy AF, et al. Circulating tumour DNA profiling reveals heterogeneity of EGFR inhibitor resistance mechanisms in lung cancer patients. Nat Commun. 2016;7:11815.

52. Thress KS, Brant R, Carr TH, et al. EGFR mutation detection in ctDNA from NSCLC patient plasma: a cross-platform comparison of leading technologies to support the clinical development of AZD9291. Lung Cancer. 2015;90(3):509-515.

53. Sundaresan TK, Sequist LV, Heymach JV, et al. Detection of T790M, the acquired resistance EGFR mutation, by tumor biopsy versus noninvasive blood-based analyses. Clin Cancer Res. 2016;22(5):1103-1110.

54. Thress KS, Paweletz CP, Felip E, et al. Acquired EGFR C797S mutation mediates resistance to AZD9291 in non-small cell lung cancer harboring EGFR T790M. Nat Med. 2015;21(6):560-562.

55. Niederst MJ, Hu H, Mulvey HE, et al. The allelic context of the C797S mutation acquired upon treatment with third-generation EGFR inhibitors impacts sensitivity to subsequent treatment strategies. Clin Cancer Res. 2015;21(17):3924-3933.
56. Woyach JA, Furman RR, Liu TM, et al. Resistance mechanisms for the Bruton's tyrosine kinase inhibitor ibrutinib. $N$ Engl J Med. 2014;370(24):2286-2294.

57. Wang S, Song Y, Yan F, Liu D. Mechanisms of resistance to thirdgeneration EGFR tyrosine kinase inhibitors. Front Med. 2016;10(4): 383-388.

58. Kobayashi Y, Azuma K, Nagai H, et al. Characterization of EGFR T790M, L792F, and C797S mutations as mechanisms of acquired resistance to afatinib in lung cancer. Mol Cancer Ther. 2017;16(2): 357-364.

59. Lin JJ, Fairclough SR, Nagly RJ, et al. Identification of on-target mechanisms of resistance to EGFR inhibitors using cfDNA next-generation sequencing. Poster presented at: 17th World Conference on Lung Cancer; December 4-7, 2016; Vienna, Austria.

60. Jia Y, Yun CH, Park E, et al. Overcoming EGFR(T790M) and EGFR(C797S) resistance with mutant-selective allosteric inhibitors. Nature. 2016;534(7605):129-132.

61. Uchibori K, Inase N, Araki M, et al. Brigatinib combined with antiEGFR antibody overcomes osimertinib resistance in EGFR-mutated non-small-cell lung cancer. Nat Commun. 2017;8:14768.
Lung Cancer: Targets and Therapy

\section{Publish your work in this journal}

Lung Cancer: Targets and Therapy is an international, peer-reviewed, open access journal focusing on lung cancer research, identification of therapeutic targets and the optimal use of preventative and integrated treatment interventions to achieve improved outcomes, enhanced survival and quality of life for the cancer patient. Specific topics covered in the journal include: Epidemiology, detection and screening Cellular research and biomarkers; Identification of biotargets and agents with novel

Submit your manuscript here: https://www.dovepress.com/lung-cancer-targets--therapy-journa

\section{Dovepress}

mechanisms of action; Optimal clinical use of existing anticancer agents, including combination therapies; Radiation and surgery; Palliative care; Patient adherence, quality of life, satisfaction; Health economic evaluations. The manuscript management system is completely online and includes a very quick and fair peer-review system. Visit http://www.dovepress.com/testimonials.php to read real quotes from published authors. 